\title{
REINFORCEMENT AND CONSOLIDATION OF MASONRY STRUCTURES. SUCCESSFUL CASES IMPLEMENTED: FROM THE STUDY TO THE EXECUTION PHASE
}

\author{
JOSE DOBÓN ${ }^{1 *}$ AND MIGUEL A. SORIA ${ }^{2}$ \\ ${ }^{1}$ Civil Engineer \\ Kerakoll Ibérica S.A. \\ Carretera de l'Alcora, Km. 10,450, 12006 Castellón de la Plana, Spain \\ e-mail: jose.dobon@kerakoll.es \\ ${ }^{2}$ Building Engineer \\ Kerakoll Ibérica S.A. \\ Carretera de l'Alcora, Km. 10,450, 12006 Castellón de la Plana, Spain \\ e-mail: miguel.soria@kerakoll.es
}

Keywords: Masonry, Structural Strengthening, Hydraulic Natural Lime Mortars, Steel Fibers, Basalt Fibers

\begin{abstract}
Traditionally, reinforcement and consolidation of masonry structures has been done according to one of the following approaches, or a combination of them: By using materials with a very different nature and behaviour from the original ones in the reinforced structure or by increasing the section of those structures, increasing, therefore, their hardness. The first approach could unleash serious setbacks in the original structure. Using materials with high elastic modulus on more flexible elements might generate new tensions in the system, which previously did not exist, compromising the reinforcement intervention. The second approach implies increasing significantly the structural geometry and, therefore, its own global hardness.
\end{abstract}

The modern approach, which reinforcement and consolidation of masonry structures pursue, is solving both, different nature of materials and sectional increasing. It is done by using compatible materials with the original structure, combining the elastic behavior of them and assuring the original breathability, and implementing low thickness interventions in order to do not modify the original hardness.

The proposal of a reinforcement system compatible with the historic and architectonic nature of the structure, is based on a mineral matrix of hydraulic natural lime, GeoCalce F Antisismico, combined with basalt fiber fabrics (GeoSteel Grid) or galvanized steel unidirectional bands (GeoSteel Hardwire ${ }^{T M}$ ). With this system typology, it is ensured an improvement in the mechanical resistances of the structure, based on a simple and low thickness application.

The aim of the exposition is introducing a reinforcement and consolidation system for masonry structures developed by Kerakoll and showing several success cases, in Spain and Italy, reinforced with this system. Each case will be explained from the initial study phase to the execution of the intervention, including the calculations to determine the application to be done. 


\section{INTRODUCTION}

The last seismic events in Italy (L'Aquila 2009, Emilia 2012, Italy center 2017) have shown the vulnerability of masonry structures. The majority of existing buildings in Europe were designed without considering seismic loads and/or the changing of usage destination. From the last 20 years, in some cases until now, engineers and architects, when they have worked in existing structures, must have interrupted their structural usage due to two factors: the available strengthening technologies are very invasive and, the most important one, they should use solutions with a wide time of installation commonly related to concrete strengthening, heavy steel profiles and sectional growths. FRCM (Fiber Reinforced Cementitious Mortar), mortar matrix reinforced with fibers and SRG (Steel Reinforced Grout), mortar matrix reinforced with steel fibers, those two systems have become the most popular ones thanks to their excellent ratio strength - weight and their relatively easiness and quickness application compared with traditional technics above-named.

The aim of the present document is demonstrating the validity of the systems already explained on the presentation and developing different successful cases that are done with these strengthening systems.

\section{MATERIALS PROPERTIES}

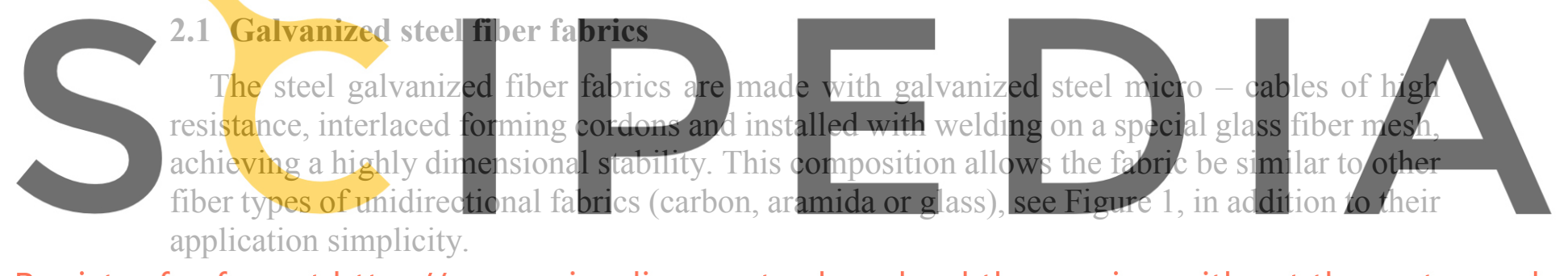

Register for free at https//www.scipedia.com to download the version without the watermark

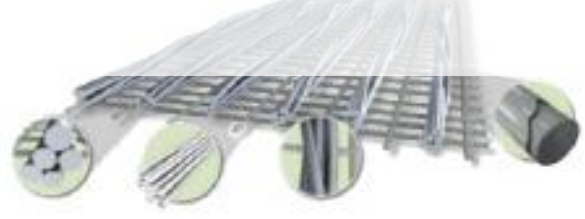

Figure 1: Page layout

Micro - cables and cordons are made accordingly to ISO/DIS 17832 standard, which describes fabrication technics and the referential parameters. Micro - cables and cordons characteristics are detailed in Table 1.

Table 1: Micro - cable and cordon characteristics

\begin{tabular}{ccccc}
\hline Material & Tensile strength (MPa) & Elastic Modulus (GPa) & Section $\left.\mathbf{( m m}^{\mathbf{2}}\right)$ & $\boldsymbol{\varepsilon}$ \\
\hline Micro - cable & 2900 & 87000 & 0,1076 & - \\
\hline Cordon 3x2 & 750 & 200000 & 0,538 & $>1,50 \%$ \\
\hline
\end{tabular}


The micro - cable interlaced allows to maintain unchanged the elastic modulus of the cordon in comparison with the micro -cables, empowering the high resistance and rigidity of steel.

Cordons are galvanized obtaining a material that is not affected by the corrosive agents and it make them appropriate for different exposure environments. Zinc coating is ruled by EN 10244 -2 being the zinc quantity great to $15,97 \mathrm{~g} / \mathrm{m}^{2}$. In Figure 2, it shows a SEM image of the 40 times augmented filament to determine the thickness and the mineralogy of the zinc coating, in order to do the process quality control.

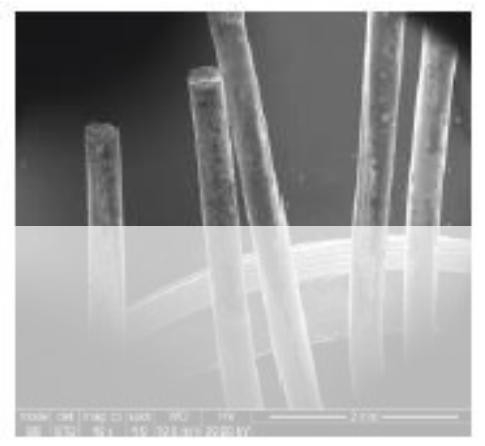

Figure 2: sole cordon SEM image

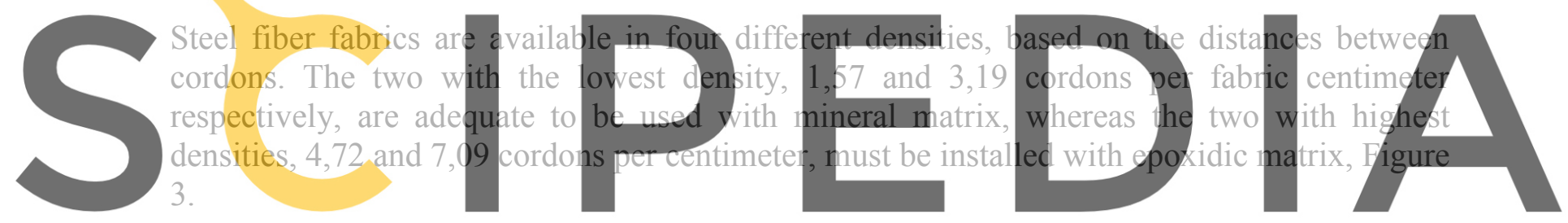

Register for free at https//www.scipedia.com to download the version without the watermark

a)

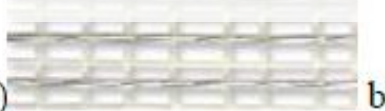

b)
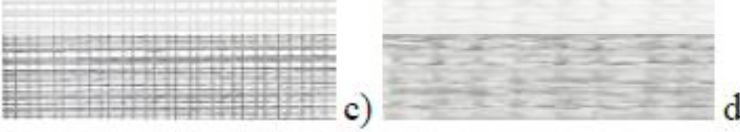

d)

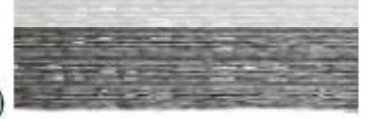

Figure 3: four different steel fiber fabrics densities, cordons per centimetre: a) 1,57; b) 3,19; c) 4,72 and d) 7,09

SRG systems present, among others, a great advantage in front of FRP composed systems: they have a considerable shear resistance when they are subjected to perpendicular actions to their guideline. This last characteristic is exclusively for this kind of fiber.

\subsection{Basalt and stainless steel fiber fabrics}

Biaxial equilibrated fabrics made of basalt fiber and stainless steel AISI 304 micro - wires, with the same grammage in both directions. The special combination, basalt and stainless steel micro - wires, ensures a high shear strength and abrasion. 


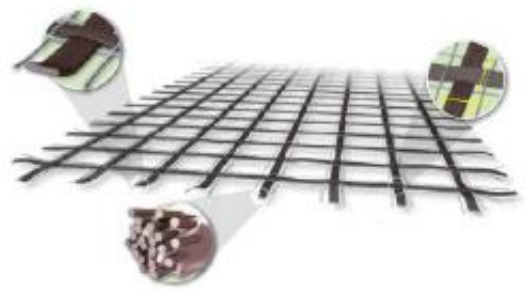

Figure 4: Stainless steel and basalt fiber fabric

Basalt fibers are the result of volcanic stone fusion and it ensures excellent mechanical and physicochemical properties in aggressive environments. The hardness of basalt fibers guarantees good tensile and shear strength, which are essential in masonry consolidation. Basalt fibers, used in GeoSteel Grid fabrics, are ruled by the normative UNI 8746 and UNI 9409.

\section{Stainless steel AISI 304 micro - wires are installed in both sides of the basalt fiber, besides its mechanical contribution to the fabric; it balances and stabilizes the fabric in any direction. Using stainless steel provides a greater ductility and shear strength to the fabric, allowing to the strengthening system a greater energy dissipation and ensuring a better security coefficient in the intervention.}

Table 2: Stainless steel AISI 304 and basalt fibers characteristics
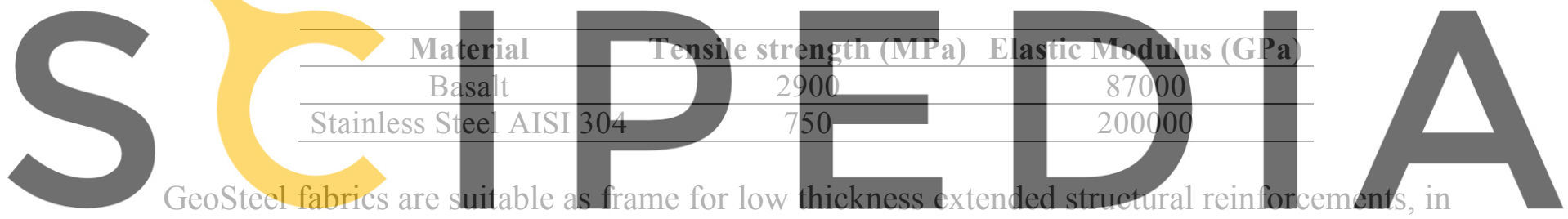

GeoSteel fabrics are suitable as frame for low thickness extended structural rein forcements, in
combination with high resistance steel fiber connectors GeoSteel or helical stainless steel bars

Register fotrefreer tit different densities, they receive their commercial name: GeoGrid 120, GeoSteel Grid 200 y GeoSteel Grid 400. In Table 3, it is shown technical properties from these three different densities:

Table 3: Technical properties of stainless steel AISI 304 and basalt fibers fabrics

\begin{tabular}{ccccc}
\hline & GeoGrid 120 GeoSteel Grid 200 GeoSteel Grid 400 \\
Technical Properties & & & & \\
& $22 \times 22$ & $17 \times 17$ & $15 \times 15$ \\
\hline Fabric dimensions $(\mathrm{mm})$ & 130 & 200 & 400 \\
\hline Density $\left(\mathrm{g} / \mathrm{mm}^{2}\right)$ & 30 & 55 & 110 \\
\hline Tensile load per width unity $(\mathrm{KN} / \mathrm{m})$ & 1600 & 1700 & 1700 \\
\hline Tensile characteristic strength $(\mathrm{MPa})$ & & & \\
\hline
\end{tabular}

The basalt fiber has a special alkali - resistant protector treatment, it consists in a resin in aqueous basis free from solvent, which gives to the fiber an additional protection. 


\subsection{Natural hydraulic lime matrix}

The matrix election is based on the type of support where is going to be the reinforcement done, for this reason, with masonry structures the selected matrix is natural hydraulic lime. The Table 4 shows different mechanical properties of this matrix, being particularly indicated for structural reinforcement in masonry structures. In them, due to their natural origin compounds, it is possible ensure the perfect adhesion, porosity, hygroscopicity and breathability with the original support, achieving a highly compatibility between the original structure and the reinforcement done.

Table 4: Mechanical properties of mineral matrix

\begin{tabular}{ccccc}
\hline Material & $\begin{array}{c}\text { Compressive } \\
\text { strength (MPa) }\end{array}$ & $\begin{array}{c}\text { Flexional } \\
\text { strength (MPa) }\end{array}$ & $\begin{array}{c}\text { Elastic Modulus } \\
\text { (GPa) }\end{array}$ & $\begin{array}{c}\text { Adhesion } \\
\text { (MPa) }\end{array}$ \\
\hline $\begin{array}{c}\text { GeoCalce F } \\
\text { Antisismico }\end{array}$ & 15 & 5 & 9230 & 0,80 \\
\hline
\end{tabular}

Table 5: Results of experimental tests ( $\%$ increased in relation to non - reinforced specimens)

Single lap (Shear test) (ASTM D3163)

Masonry walls (diagonal compressive test)

Vaults (asymmetric load in a fourth part of the span)

Masonry walls in U sha table, peak
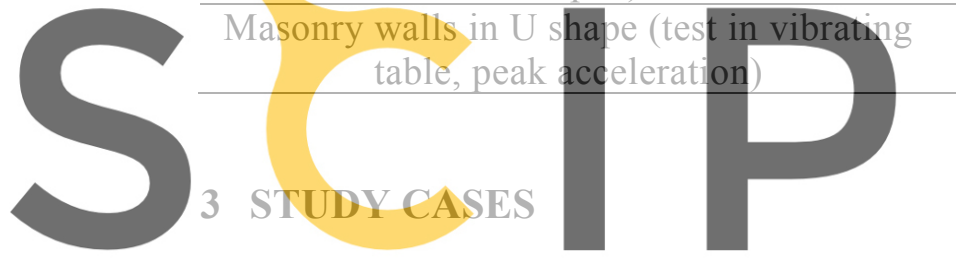

$60 \%$ (4 cordons per inch), 30\% (8 cordons per inch) for the fibers tensile strength From $230 \%$ to $527 \%$ (SRG)

$355 \%$ (extrados SRG)
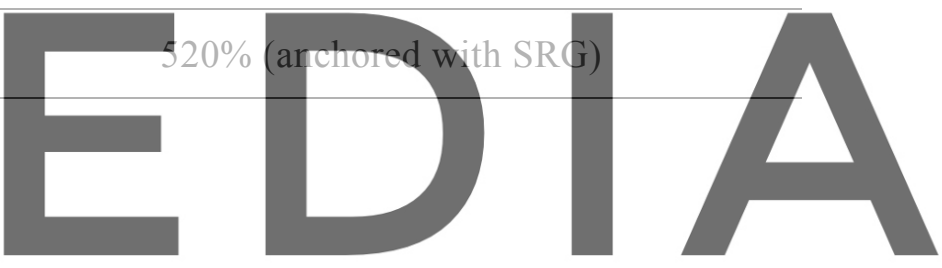

The following study cases represent, among others, FRCM and SRG typical applications of structural

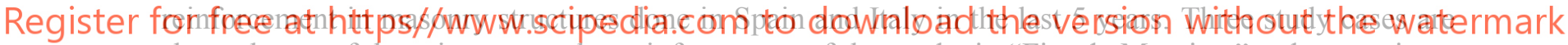
showed: one of them is an extrados reinforcement of the vaults in "Fira de Montjuïc", other one is an extrados reinforcement of the dome of San Vicenç Church in Saurí and the last one is a wall reinforcement in the Botanic Garden in Pisa.

\subsection{Vaults - Fira Montjuïc - Barcelona}

The vaults are cracked, they are visible from its intrados and distributed along their ribs. After the analysis, it is determined that the degradation cause is the lack of waterproofing in the vaults affecting to their structural integrity. It is decided to do a structural reinforcement by the extrados vault, due to their intrados can not be covered by esthetical reasons. Together with the intervention, the cause of the degradation is removed by waterproofing the vault with materials capable of ensuring the transpirability balance and with an elastic behavior similar to the original structure.

The procedure for doing the structural reinforcement is as follows:

1. Removal of old coatings

2. Support preparation

3. Application of the structural reinforcement mortar, GeoCalce F Antisismico. 
4. Installation of the GeoSteel G600 fabric.

5. Fabric anchor $>30 \mathrm{~cm}$.

6. Application of the structural reinforcement mortar, GeoCalce F Antisismico, in order to cover the fabric.

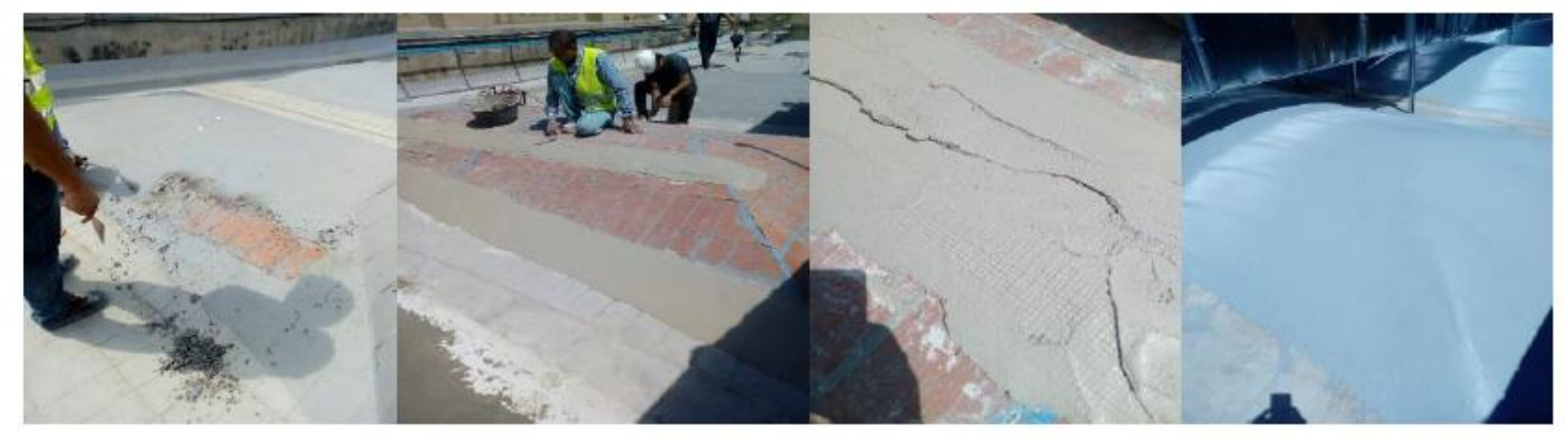

Figure 5: Vaults extrados

In Figure 5, it is shown the different installation phases of the structural reinforcement and the waterproofing system applied. This treatment ensures the transpirability of the support materials.

3.2 Masonry wall - Botanic Garden - Pisa

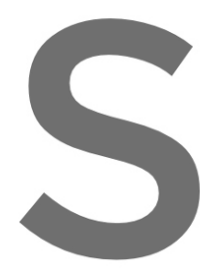

The Botanic Garden is $27000 \mathrm{~m}^{2}$ approxima

perimeter wall with a vering

and its function is to protect the arboreal spec

wall made, mainly, with bricks with different
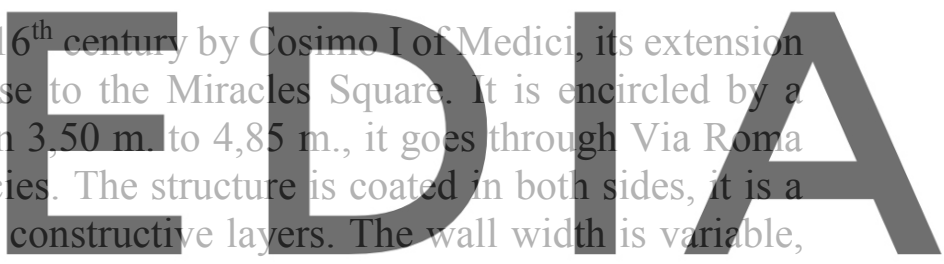

from $30 \mathrm{~cm}$. in the south zone where we can find a framed structure with concreate, to $41 \mathrm{~cm}$.

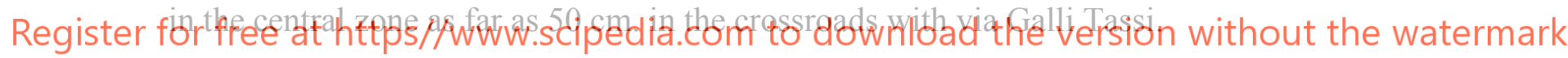

The deformation's diagram shows the tipping phenomena up to $9 \mathrm{~cm}$, which are achieved due to the hystoric vegetation located close to the perimeter. Their roots go through the wall foundation and enter into the pavement, even breaking it. In these zones, where the vegetable level is higher than $80 \mathrm{~cm}$, there is humidity over the wall at the outside zone. It degrades the coating and disaggregate the surface (Figure 6).

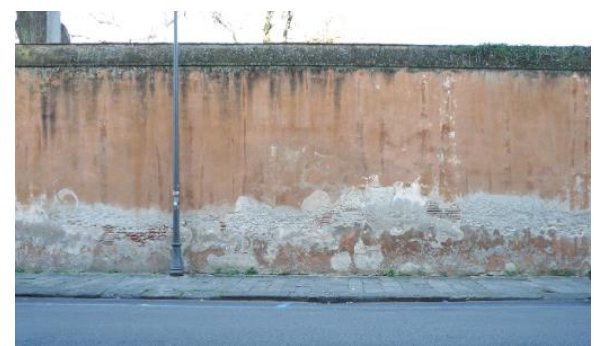

Figure 6: Perimeter wall status 
In July of 2010, a sudden collapsing event took place in a part of wall, in a bordering zone between a private garden and the Botanical Garden. The prominent vulnerability accompanied by the degradation and the clear tipping, mainly related to the vegetable species nearby, were the precursor in the summer of 2011 for the implementation of anti-tipping interventions along the street. It was installed, each three sections of $40 \mathrm{~m}$. approximately, two inclined metallic braces anchored to a micropiles foundation fitted in the Botanic Garden land. The structure support is made by a metallic beams grid, installed over the wall surface.

In 2016, the consolidation intervention was done. The intervention was thought for ensuring the static security of the wall against the tipping danger due to horizontal actions (seismic and wind), meanwhile ensuring a ductile behavior of the masonry in front of plants roots disaggregation actions.

With this purpose, the wall part that goes along Via Roma was reinforced with buttress built in situ, installed every $6 \mathrm{~m}$. in continuity with the original structure and consolidated over the micropiles foundation.

The masonry walls between buttresses were reinforced facing flexional stresses supposing a continue beam diagram. It was made with longitudinal bands, GeoSteel G600, installed with natural lime hydraulic structural mortar, GeoCalce F Antisismico.
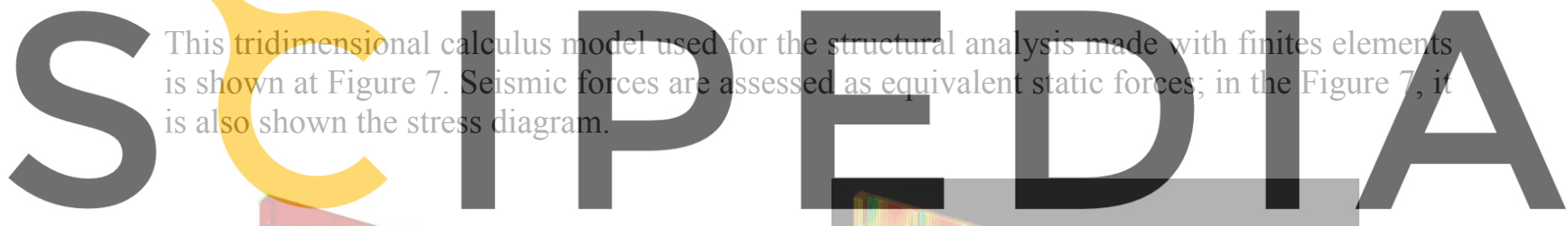

Register for free at https//www.scipedia.com to download the version without the watermark

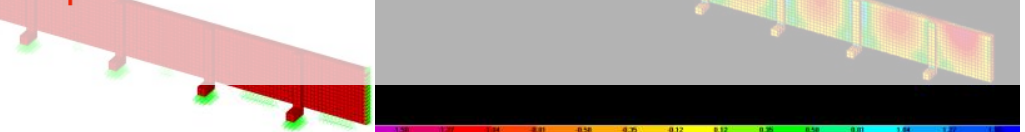

Figure 7: Structure modelling and stress diagram

With the intervention done is ensured the old wall stability of the Botanic Garden against wind forces and it increases the security level against seismic forces.

\subsection{Barrel vaults - San Vicenç de Saurí Church - Sort}

San Vicenç de Saurí is the parochial church of Saurí village, in the municipal district of Sort, in Pallars Sobirà region. The church construction is estimated around the year 852, its style is Baroque. It is a church with a sole nave, built on stone; in addition, it has the typical Pyrenean bell tower on an octagonal floor plan and a main deck. It is a protected building as a "Bien Cultural de Interés Local". Moreover, it was aesthetically restored on the inside by Santi Moix, an international artist born in this village.

Together with the restoration work, they studied the old stone structure and its barrel vaults of 
an area of $25 \mathrm{~m}^{2}$ approximately in order to ensuring the structural building stability. From that study, it was determined the need to strengthen the vaults due to its low thickness and the existence of cracks on them.

The proposal done is the one on shown on Figure 8:

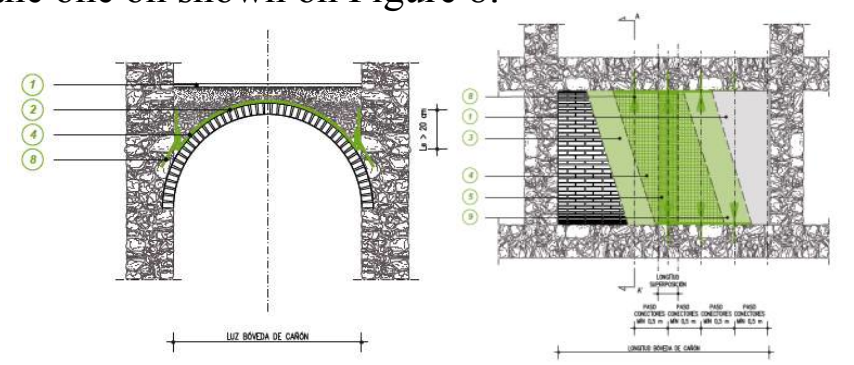

Figure 8: Extended extrados reinforced system for barrel vaults schema

The procedure schemed of the reinforced system is as follows:

1. Removal of old coatings

2. Support preparation

3. Application of the structural reinforcement mortar, GeoCalce F Antisismico.

4. Installation of the GeoSteel Grid 2000 fabric.

Overlap length $>30 \mathrm{~cm}$.

6. Anchor length $>20 \mathrm{~cm}$

7. Overlap anchor length

8. Mechanical connector reinforcement

The reinforcement done helps to avoid the vaults from the
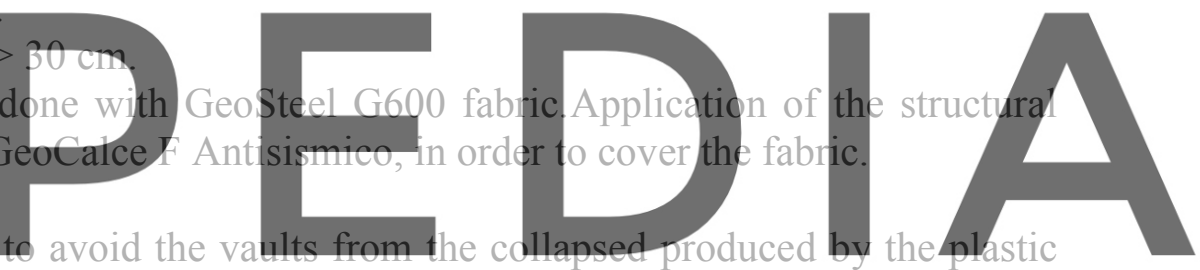

joints due to the lack of tensile strength of the masonry. This typology of reinforcement helps

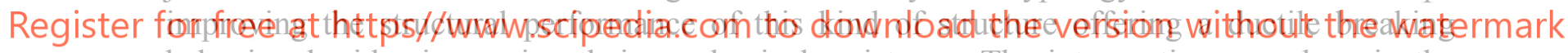

behavior, besides improving their mechanical resistance. The intervention was done in the

following phases, as shows Figure 9:
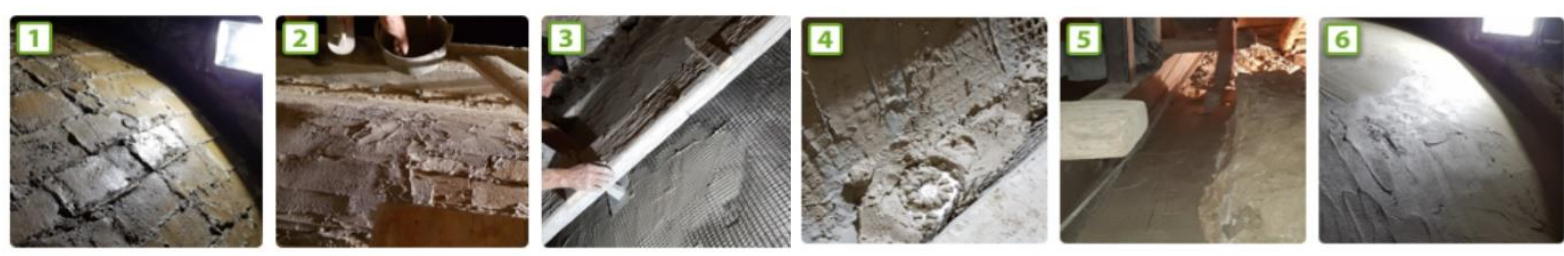

Figure 9: Phases done during the vaults reinforcement application

\section{CONCLUSIONS}

Since 2004, when using high - resistance steel fiber bands started on civil engineering applications, several studies took place in order to study its mechanical properties and effectiveness as external reinforcement elements. The benefit of installing steel bands or stainless steel and basalt fiber biaxial fabrics in combination with mineral mortars, instead of organic mortars, is that SRG/FRCM systems are a versatile reinforcement technology thanks to 
its compatibility with the original structure and its easy application. The interventions explained through this document are a clear example of validity as a structural reinforcement system. It is demonstrated that SRG/FRCM systems, improve the bearing capacity of the structure subjected to different stresses, static as well as dynamic, which are not capable of stand design loads, helping to preserve from deterioration. Moreover, they improve the structural ductility in comparison with other more traditional structural reinforcements, such as FRP systems.

The studies done, as well as the different applications made with these systems, have demonstrated, without doubt, that this new kind of composite materials must be included in the range of composite materials intended for structural reinforcement. At the same time, these systems are used with mineral mortars, offering a better response and compatibility with the original structure.

\section{PEFEPENCES}

[1] Casadei P. and Agneloni E. Advance composites applications on historical structures in Italy: Case studies and future developments 6th International Conference on Structural Analysis of Historical Construction - Preserving Safety and Significance, Bath, United Kingdom, July 2-4, 2008, ISBN Vol.2:978-0-415-48107-6.

[2] Casadei P. and Agneloni E. Case Studies on Advanced Composite Materials for Civil Engineering and Architectural Applications Structural Engineering International, vol.21,

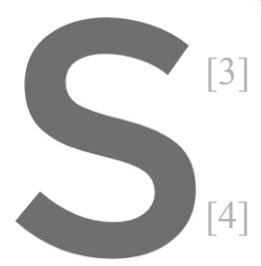
3/2011, 271-278
Casadei P., Nanni A., Alkhrdaji T., Tho
concrete beams strengthened with Stee
2005;8(4):427-442.
Casadei P., Nanni. A., Alkhrdaji T. Steel-Rein material for strengthening th infrastructures
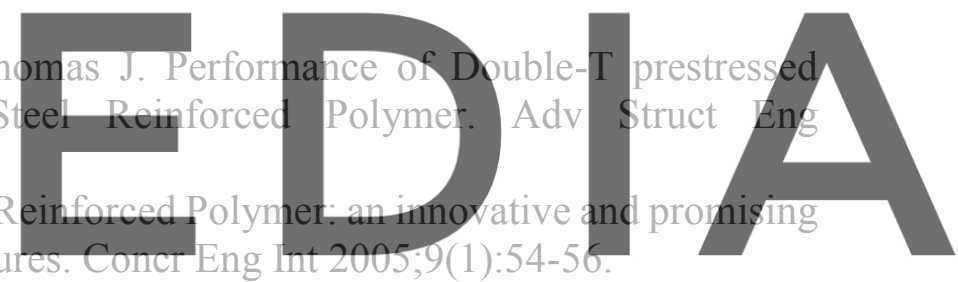

[5] De Santis S., de Felice G., Napoli A., Realfonzo R Strengthening of Structures with Steel

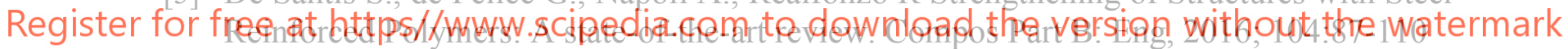

[6] De Santis S., Casadei P., De Canio G., de Felice G., Malena M., Mongelli M., Roselli I. Seismic performance of masoniry walls retrofitted with steel reinforced grout. Earthquake Engineering and Structural Dynamics, 2016;45(2):229-251. DOI: 10.1002/eqe.2625.

[7] De Santis S., Casadei P., de Felice G. Tests on the bond performance of mortar based strengthening systems on masonry substrates. Proc. Int. Conf. IMC'14 - 9th International Masonry Conference (Guimarães, Portugal, 7-9 July 2014). ISBN: 978-972-8692-85-8.

[8] Faella C, Napoli A, Realfonzo R. Seismic behaviour of RC beam-column joints strengthened with steel fiber composite materials. In: Proceedings of XVI Convegno ANIDIS, L'Aquila, 2015 (in Italian).

[9] Napoli A., Realfonzo R., Casadei P. Rinforzo a flessione di solette in c.a. con sistemi in SFRP/SFRCM. In: Proceedings of XX Congresso CTE, Milano, Italy, 2014 (in Italian).

[10] Napoli A., Realfonzo R., Petracca M., Candeloro F., Camata G., Casadei P. Flexural strengthening of RC slabs with SRP/SRG: an experimental-numerical comparison. In: Proceedings of ACE 2015, Vietri sul Mare, Salerno, Italy, 2015.

[11] Napoli A., Realfonzo R. Compressive behavior of concrete confined by SRP wraps. Construction and Building Materials 2016 (in press). 